\title{
EXPERIMENTAL INVESTIGATION OF FLOW CONDENSATION IN MICROGRAVITY
}

\author{
Hyoungsoon Lee \\ Purdue University \\ West Lafayette, IN, USA \\ Christopher Konishi \\ Purdue University \\ West Lafayette, IN, USA
}

\author{
Ilchung Park \\ Purdue University \\ West Lafayette, IN, USA \\ Issam Mudawar* \\ Purdue University \\ West Lafayette, IN, USA
}

\author{
James D. Wagner \\ NASA Glenn Research Center \\ Cleveland, OH, USA \\ Mohammad M. Hasan \\ NASA Glenn Research Center \\ Cleveland, OH, USA
}

\author{
Jeffrey R. Mackey** \\ Vantage Partners, LLC \\ Brook Park, OH, USA
}

\begin{abstract}
Future manned missions to Mars are expected to greatly increase the space vehicle's size, weight, and heat dissipation requirements. An effective means to reducing both size and weight is to replace single-phase thermal management systems with two-phase counterparts that capitalize upon both latent and sensible heat of the coolant rather than sensible heat alone. This shift is expected to yield orders of magnitude enhancements in flow boiling and condensation heat transfer coefficients. A major challenge to this shift is a lack of reliable tools for accurate prediction of two-phase pressure drop and heat transfer coefficient in reduced gravity. Developing such tools will require a sophisticated experimental facility to enable investigators to perform both flow boiling and condensation experiments in microgravity in pursuit of reliable databases. This study will discuss the development of the Flow Boiling and Condensation Experiment (FBCE) for the International Space Station (ISS), which was initiated in 2012 in collaboration between Purdue University and NASA Glenn Research Center. This facility was recently tested in parabolic flight to acquire condensation data for FC-72 in microgravity, aided by high-speed video analysis of interfacial structure of the condensation film. The condensation is
\end{abstract}

* Corresponding author; Tel. (765) 494-5705; Fax (765) 494-0539; E-mail: mudawar@ecn.purdue.edu;

Website: https://engineering.purdue.edu/BTPFL

** This author was affiliated with ARSR Aerospace Corporation at the time this research was performed. achieved by rejecting heat to a counter flow of water, and experiments were performed at different mass velocities of FC-72 and water and different FC-72 inlet qualities. It is shown that the film flow varies from smooth-laminar to wavy-laminar and ultimately turbulent with increasing FC-72 mass velocity. The heat transfer coefficient is highest near the inlet of the condensation tube, where the film is thinnest, and decreases monotonically along the tube, except for high FC-72 mass velocities, where the heat transfer coefficient is enhanced downstream. This enhancement is attributed to both turbulence and increased interfacial waviness. One- $g_{e}$ correlations are shown to predict the average condensation heat transfer coefficient with varying degrees of success, and a recent correlation is identified for its superior predictive capability, evidenced by a mean absolute error of $21.7 \%$.

Keywords: microgravity; condensation; annular flow

\section{INTRODUCTION}

1 Thermal Management in Future Space Missions

Following the Apollo manned missions to the Moon in the 1960 s and 1970s, interest shifted to manned missions to Mars, which are expected to greatly increase mission scope, size, complexity and duration compared to any previous space endeavor. Associated with these increases are unprecedented increases in both power requirements and heat dissipation demands. Because the success and cost of a space mission are highly influenced by size and weight, reducing both, including 
those of all thermal management sub-systems, is paramount to the feasibility of future, more demanding missions $[1,2]$.

By far, the most effective means to reducing the size and weight of thermal management sub-systems is to transition from single-phase to two-phase heat transport. By capitalizing upon the coolant's latent and sensible heat rather than sensible heat alone, two-phase systems can yield orders of magnitude enhancement in evaporation (or boiling) and condensation heat transfer coefficients compared to single-phase counterparts. These improvements are evident from findings of several NASA workshops that resulted in specific recommendations concerning the need to incorporate flow boiling and condensation in a number of space sub-systems, such as Rankine cycle power conversion, thermal control systems, and advanced life support systems [3]. A recent report by the National Research Council (NRC), which was submitted to the U.S. Congress in 2011, provided an agenda for critical research needs in both life and physical sciences for future space exploration [4]. In the NRC report, specific recommendations were made by individual panels that placed heavy emphasis on reduced-gravity two-phase flow and heat transfer, including the need for databases, correlations, theoretical models, and computational tools.

\section{Thermal Control Systems}

Thermal Control Systems (TCSs) play a vital role in life support in space vehicles and planetary bases. These systems are responsible for controlling the temperature and humidity of the environment. With increased duration and complexity, future space missions will demand TCS architectures with significantly reduced power input, mass and volume. The TCS must tackle three primary tasks, heat acquisition, heat transport and heat rejection. Heat acquisition components acquire energy from heatproducing sources by evaporation or flow boiling and transfer it to the TCS. Heat transport components move the energy from the heat acquisition sources to heat rejection components. By condensing the working fluid, the heat rejection components reject the heat from the TCS to the external environment.

The merits of boiling are realized in a variety of configurations, including pool boiling [5], channel flow boiling [6], jets [7-9], and sprays [10,11], especially when implemented with surface

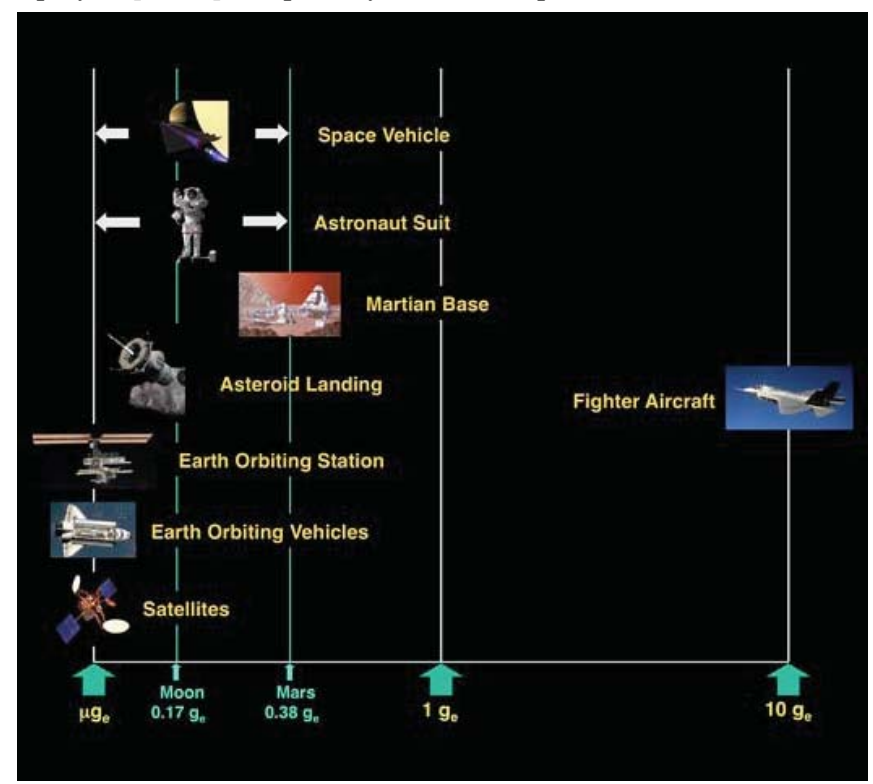

Fig. 1 Examples of Demanding Predictive Models of the Effects of Gravity on Two--Phase Flow of Heat Transfer enhancement $[12,13]$. However, the configuration most crucial to the understanding of reduced-gravity boiling is flow boiling in tubes, which is also the most likely configuration for adoption in a TCS. Similarly, the most crucial condensation configuration is flow condensation in tubes..

\section{Fundamental Research Needs Related to Flow Boiling and Condensation in Reduced Gravity}

Because of the large density differences between liquid and vapor, buoyancy can play a vital role in defining the motion of vapor relative to liquid. Consequently, these density differences can have a profound influence on heat transfer by flow boiling and condensation. Because most predictive tools for two-phase heat transfer are derived from experiments that have been conducted at one $g_{e}$, it is impossible to ascertain the validity of the same tools for reduced gravity conditions, especially microgravity, without performing tests in the appropriate gravitational environment. As shown in Fig. 1, space missions span a fairly broad range of gravities, including microgravity for satellites and Earth-orbiting vehicles and stations, and Martian gravity for the Martian habitat. Therefore, existing flow boiling and condensation pressure drop and heat transfer correlations and models must be updated, or new ones developed, to tackle the complexities of operation in reduced gravity.

\section{Condensation Heat Transfer Regimes and Predictive Tools}

Condensers are commonly found in power generation, chemical, food and pharmaceutical industries, as well as in domestic refrigeration and air conditioning systems. Falling film condensers rely entirely on gravity to achieve condensate film motion on the surfaces of either vertical tubes or plates, or horizontal tube banks, but in most other types of condensers the film is shear-driven by the vapor flow. The heat transfer performance of a condenser is largely dependent on the formation and transport behavior of the condensate film. For condensation inside tubes, the flow transitions from a pure vapor flow regime to an annular flow regime once the condensate film begins to form along the inner walls, driven mostly by vapor shear and influenced, to a lesser extent, by gravity. Heat transfer in the upstream portion of the annular region is dominated by pure conduction, but as the film continues to thicken along the tube length, the film flow may turn turbulent and the heat transfer become dominated by turbulent eddies. If the tube is long enough, the film thickening, aided by interfacial waves, may cause bridging of liquid films across the vapor core and a transition to the slug flow regime. The oblong slug flow bubbles gradually decrease in length and are replaced by smaller spherical bubbles, which mark the initiation of the bubbly flow regime. Eventually, the vapor is fully condensed and a pure liquid flow regime is established.

The annular flow regime is especially important to the performance of most condensers because this regime both contributes the highest heat transfer coefficients and generally occupies the largest fraction of the tube length. Past studies on annular condensation in tubes have resulted in three different approaches to predicting the condensation heat transfer coefficient: (a) semi-empirical correlations [14-18], with an application range that is limited to the databases upon which these correlations are based, (b) "universal" correlations that are derived from consolidated databases from many sources, that are applicable to a wide variety of working fluids and over broad ranges of hydraulic diameter, mass velocity, quality and pressure [19,20], and (c) theoretical control-volume-based models [21,22]. 


\section{OBJECTIVES OF STUDY}

The present study is a part of a long-term NASA-supported project that was initiated in 2012 as a prelude to the development of the Flow Boiling and Condensation Experiment (FBCE) for the International Space Station (ISS). The overall objectives of the long-term NASA project are to: (a) obtain flow boiling and condensation databases in microgravity, (b) develop an experimentally validated, mechanistic model for flow boiling critical heat flux (CHF) in microgravity and criteria to predict the minimum flow rate required to ensure gravity-independent $\mathrm{CHF}$, and (c) develop an experimentally validated, mechanistic model for condensation in microgravity and criteria to predict the minimum flow rate required to ensure gravity-independent annular condensation. This study concerns the condensation portion of the project. Parabolic-flight microgravity experiments are performed using a facility that is similar in construction to the future ISS FBCE using FC-72 as condensing fluid. Presented in this paper are axial variations of the condensation heat transfer coefficient for different flow rates and inlet qualities of FC-72, and different flow rates of the cooling water. Also presented are results from flow visualization experiments that track the axial development of the condensate film. The heat transfer coefficient results are compared to predictions of prior correlations for condensation in tubes.

\section{EXPERIMENTAL METHOD}

\section{Flow Condensation Modules for Heat Transfer} Measurements and Flow Visualization

A parabolic flight condensation facility is used to facilitate both detailed heat transfer measurements and flow visualization of the condensing film. Two separate condensation modules are employed: condensation module CM-HT, which is used exclusively for heat transfer measurements, and condensation module CM-FV for flow visualization. The reason for using two separate modules is as follows. To perform heat transfer measurements for condensation along a circular tube, CM-HT features FC-72 vapor condensation along a circular metallic tube by rejecting heat to a counter flow of water through an annulus between the tube and an outer channel. Because this configuration precludes optical access to the condensing film, the flows are reversed in CM-FV, where the FC-72 vapor condenses on the outer wall of the metallic tube within the annulus by rejecting heat to water flowing in the opposite direction along the inner tube. With this second configuration, the condensing FC-72 film is made visible through the transparent walls of the outer channel. Both condensation modules features machine polished 304 stainless steel tubes for condensation. FC-72 is a very wetting fluid, with a contact angle on metallic and nonmetallic surfaces of less than 10 degrees.

\subsection{Condensation Module CM-HT for Heat Transfer Measurements}

Figure 2(a) shows a cross-sectional diagram of CM-HT. The FC-72 vapor flows through a central 304 stainless steel tube with a $7.94-\mathrm{mm}$ o.d. and $0.41-\mathrm{mm}$ wall thickness. The condensation is achieved by rejecting heat to a counter flow of water through an annulus having an outer diameter of $12.7 \mathrm{~mm}$. Stainless steel is selected for inner tube material because of its low thermal conductivity compared to other metals, which helps minimize axial conduction effects, allowing predominantly radial heat transfer between the two fluids. The small wall thickness of the inner tube serves a similar purpose in addition to minimizing the temperature gradient across the wall and helping achieve fast thermal response during parabolic flight experiments. In selecting the wall thickness for the inner tube, these important thermal considerations are carefully weighed against mechanical strength requirements of the

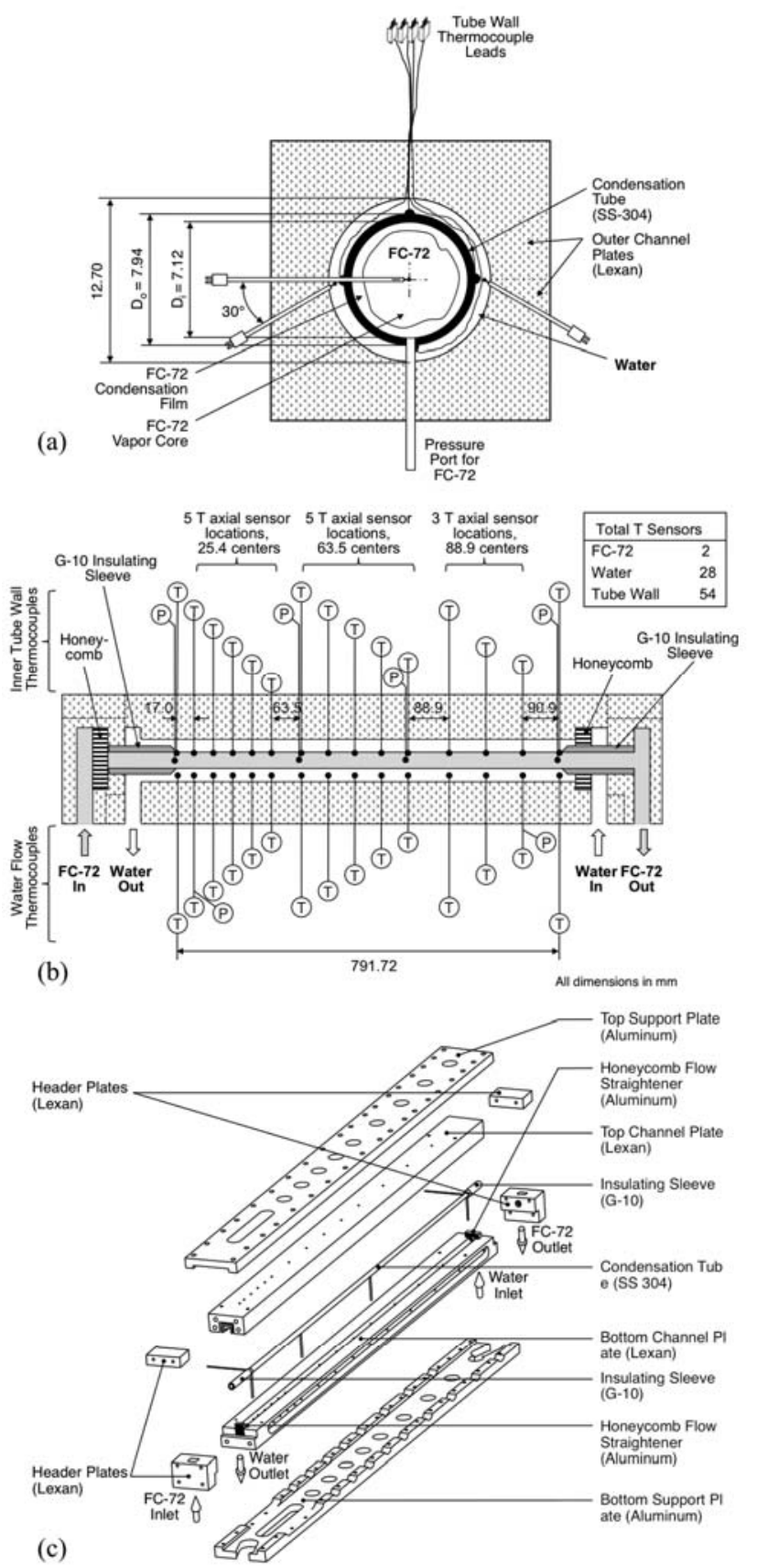

Fig. 2 Construction of condensation module CM-HT for heat transfer measurements: (a) cross-sectional diagram, (b) longitudinal sectional diagram, and (c) parts and assembly

test section under fluctuating gravity field. With a low conductivity of $0.20 \mathrm{~W} / \mathrm{m} . \mathrm{K}$, the outer polycarbonate plastic (Lexan) channel helps minimize heat loss from CM-HT to the ambient.

Figure 2(b) shows a longitudinal section of CM-HT. The FC72 vapor is introduced from the left header, which contains an aluminum honeycomb flow straightener to ensure uniform flow into the inner tube. The water is supplied through the right header, which also contains a honeycomb flow straightener for the water flow. Notice that the inner stainless steel tube is fitted with low conductivity $(0.20 \mathrm{~W} / \mathrm{m} . \mathrm{K})$ fiberglass plastic (G-10) sleeves with a 


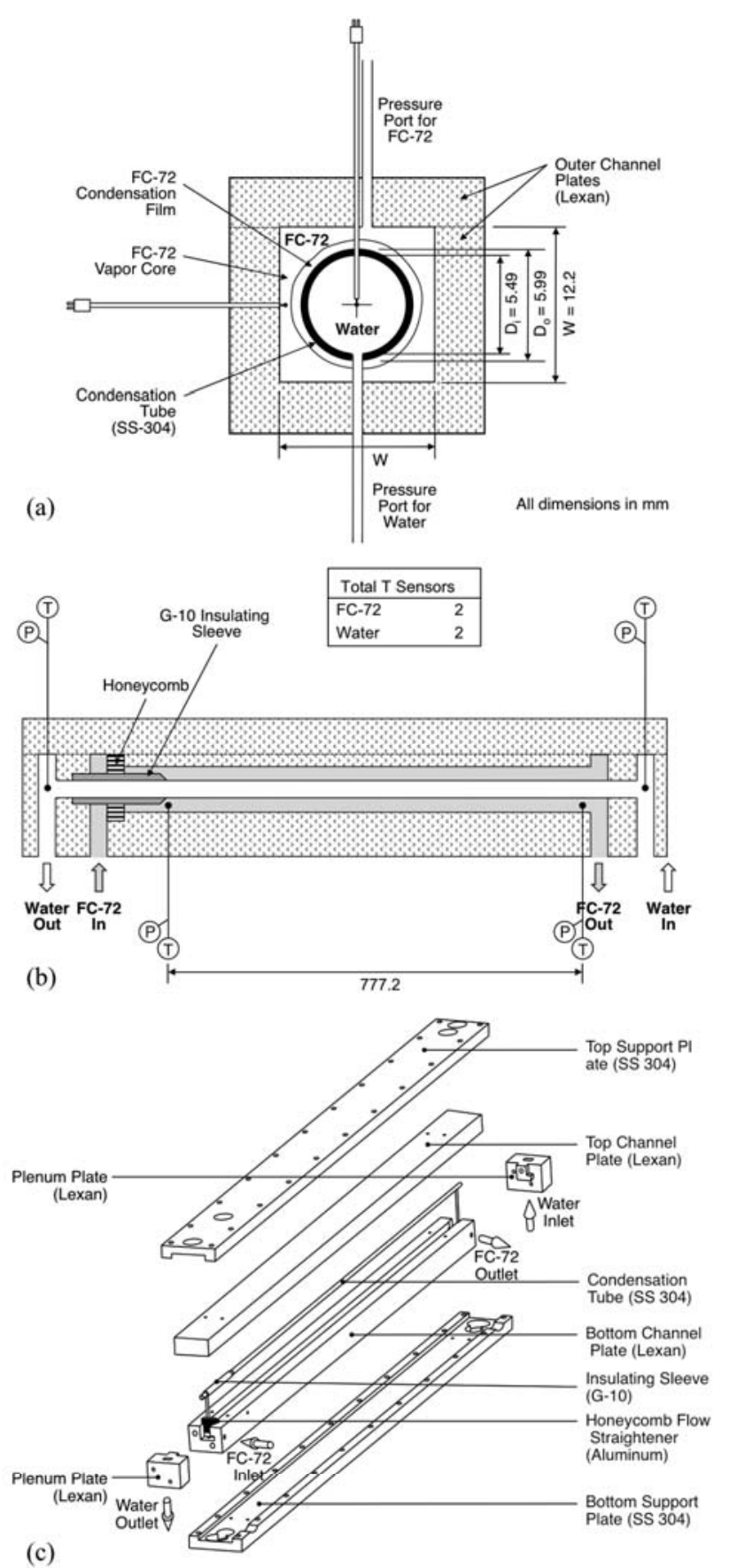

(c)

Fig. 3 Construction of Condensation Module CM-FV for Flow Visulization: (a) Cross-Sectional Diagram, (b) Longitudinal Sectional Diagram, and (c) Parts and Assembly

11.1-mm o.d. on both ends of the central tube. The primary purposes of the sleeve along the FC-72 inlet are to (1) define the precise location for the inlet to the condensing portion of the inner tube, and (2) provide a non-condensing inlet length of $71.4 \mathrm{~mm}(10$ times the inner diameter) to ensure fully developed vapor flow at the inlet to the condensing length. The 46.7-mm long sleeve on the opposite side serves the purposes of (1) defining the precise location of the downstream edge of the condensing portion of the inner tube, and (2) minimizing upstream heat loss from the incoming water. The total condensing length of the inner tube between the G-10 sleeves is $791.72 \mathrm{~mm}$ compared to a total tube length of $909.83 \mathrm{~mm}$. The sleeves have a mild 6.8-degree taper at both ends of the condensing length to minimize any wake effects.

Figure 2(c) shows the parts and assembly of CM-HT. Aside from the inner stainless steel tube, two G-10 sleeves, and two flow straighteners, this module contains six separate polycarbonate plastic (Lexan) parts: outer channel's top and bottom plates, two blocks comprising the FC-72 inlet header, and two blocks comprising the water inlet header. The outer channel's top and bottom plates are sandwiched between two thick aluminum plates that help stiffen the entire assembly. The aluminum plates are aligned with the CM-HT parts with the aid of dowel pins. Because of the relatively large number of possible leak paths, several sealing techniques were adopted throughout CM-HT. The two plenum blocks are secured to the outer channel plates with screws that trap Buna-N o-rings, and secured with Gore-Tex joint sealant and/or silicone sealant. To strengthen the bolted assembly, the threads in the Lexan parts are reinforced with stainless steel helicoil inserts.

Figures 2(a) and 2(b) show detailed locations for the temperature and pressure measurements in CM-HT. There are 84 stations for temperature measurements using type-T thermocouples. Limited access to thermocouple wires during assembly reduced the number of thermocouples actually installed. Of the 28 pairs of stations available at 15 axial locations, 22 pairs are actually populated with thermocouples to measure the axial temperature distribution for water. Figure 2(a) shows the pairs are positioned at 90- and 270-degree orientations at each instrumented axial location to check for any asymmetry in the water temperature during microgravity experiments. The inner tube wall temperature is measured at the same axial locations as the water measurements, with four thermocouples used at each instrumented axial location to check for circumferential symmetry of the wall temperature. Of a total of 54 stations available in CM-HT for wall temperature measurements, 39 are actually populated with thermocouples. Figure 2(b) shows the axial pitch of both the water and wall thermocouples is smaller near the FC-72 inlet and increases towards the opposite end. This is intended to capture the large variations of the condensation heat transfer coefficient near the FC-72 inlet where the annular condensing film begins to form. The FC-72 temperature is measured at the inlet and outlet of the condensation length as shown in Fig. 2(b). Fine thermocouple wire (36 gauge) is used to minimize disturbances to the water flow.

The CM-HT pressures are measured using Honeywell STJE absolute pressure transducers at four axial locations for FC-72 and two locations for water. Liquid-filled pressure gauges are installed at the same locations to make certain all transducers are in proper working order.

\subsection{Condensation Module CM-FV for Flow Visualization}

Figures 3(a) - 3(c) show the detailed construction of CM-FV. Aside from switching fluids (FC-72 and water) between the inner stainless steel tube and annulus, CM-FV is fairly similar in construction to CM-HT. The outer channel is made from four Lexan parts, upper and lower channel plates and two end header blocks; these parts are connected together and sealed in the same manner as in CM-HT. CM-FV also features both an inlet honeycomb flow straightener and inlet G-10 sleeve. The assembly is sandwiched between two thick stainless steel reinforcement plates with the various layers lined up with the aid of dowel pins.

Another key difference in the construction of the outer channel is the use of flat rather curved inner surfaces, which is intended to facilitate undistorted optical access to the FC-72 film condensing along the outer wall of the stainless steel tube. The 
Table 1 Thermophysical Properties of Saturated F-72 at $62 \mathrm{C}$ $(\mathrm{P}=1.21$ bar $)$

\begin{tabular}{|cccccccc|}
\hline $\begin{array}{c}k_{f} \\
{[\mathrm{~W} / \mathrm{m} . \mathrm{K}]}\end{array}$ & $\begin{array}{c}\mu_{f} \\
{[\mathrm{~kg} / \mathrm{m} \cdot \mathrm{s}]}\end{array}$ & $\begin{array}{c}c_{P f} \\
{[\mathrm{~J} / \mathrm{kg} \cdot \mathrm{K}]}\end{array}$ & $\begin{array}{c}\sigma \\
{[\mathrm{mN} / \mathrm{m}]}\end{array}$ & $\begin{array}{c}h_{f} \\
{[\mathrm{~kJ} / \mathrm{kg}]}\end{array}$ & $\begin{array}{c}h_{f g} \\
{[\mathrm{~kJ} / \mathrm{kg}]}\end{array}$ & $\begin{array}{c}\rho_{f} \\
{\left[\mathrm{~kg} / \mathrm{m}^{3}\right]}\end{array}$ & $\begin{array}{c}\rho_{g} \\
{\left[\mathrm{~kg} / \mathrm{m}^{3}\right]}\end{array}$ \\
\hline 0.0532 & $409 \times 10^{-6}$ & 1,110 & 7.8 & 101.93 & 93.03 & 1,578 & 15.86 \\
\hline
\end{tabular}

inner tube has a 5.99 -mm o.d., wall thickness of $0.254 \mathrm{~mm}$, and total length of $896.11 \mathrm{~mm}$. With the inlet G-10 sleeve, the condensation length is $777.24 \mathrm{~mm}$. Temperatures and pressures are measured at the inlet and outlet of each fluid stream.

\section{Condensation loop}

Figure 4 shows a schematic diagram of the condensation facility. The facility employs two separate sub-loops, one for FC72 and the other for water. FC-72 has a relatively moderate boiling point of $56^{\circ} \mathrm{C}$ at 1 bar and both surface tension and latent heat far smaller than those of water. Table 1 shows a summary of thermophysical properties of FC-72 at $T_{\text {sat }}=62{ }^{\circ} \mathrm{C}$, which is close to the average FC-72 temperature used in the present study. The same two-phase loop is used to condition the FC-72 to the desired mass flow rate, temperature and pressure for both condensation modules.

As shown in Fig. 4, the FC-72 is circulated with the aid of a magnetically driven Micropump GA gear pump. Exiting the pump, the FC-72 liquid passes through a flow control valve followed by a filter and a Flow Technology Omniflo turbine flow meter. The liquid is then heated along two separate Hotwatt
EM1.2-11 inline electrical pre-heaters, bringing the FC-72 to the desired quality as it enters the desired test module. Electrical power input to the pre-heaters is measured with Yokogawa WT200 and WT210 power meters. Two thermocouples are attached directly to the heating surface of each pre-heater to track internal surface temperatures. These thermocouples are connected to an Omega CN606TC2 relay, which is programmed to automatically cut off power input to the pre-heaters should the surface temperatures exceed $150{ }^{\circ} \mathrm{C}$. This temperature limit is intended to prevent any breakdown of FC-72, which may lead to formation of the toxic compound perfluoroisobutene (PFiB).

The facility is configured such as either CM-HT or CM-FV can be tested at a given time. From the pre-heaters, the FC-72 is routed to the desired module with the aid of two three-way valves. Exiting the desired test module, the two-phase FC-72 mixture is routed into a Lytron liquid-to-air heat exchanger, which returns the mixture to liquid state. A Flexicraft Hydropad-14 accumulator is employed to set a reference pressure point for the FC-72 sub-loop. The accumulator features metallic bellows inside which the FC-72 liquid can expand or contract in response to changes in the total volume of FC-72 vapor generated in the loop as well as any thermal expansion or contraction of the FC-72 liquid. The accumulator pressure is set by charging nitrogen gas into the accumulator's cavity surrounding the bellows prior to initiating the tests.

Using either CM-HT or CM-FV, the FC-72 vapor is condensed by rejecting heat to a counter-flow of water that is conditioned by the water sub-loop. The water is supplied to the desired condensation module at near ambient temperature with the

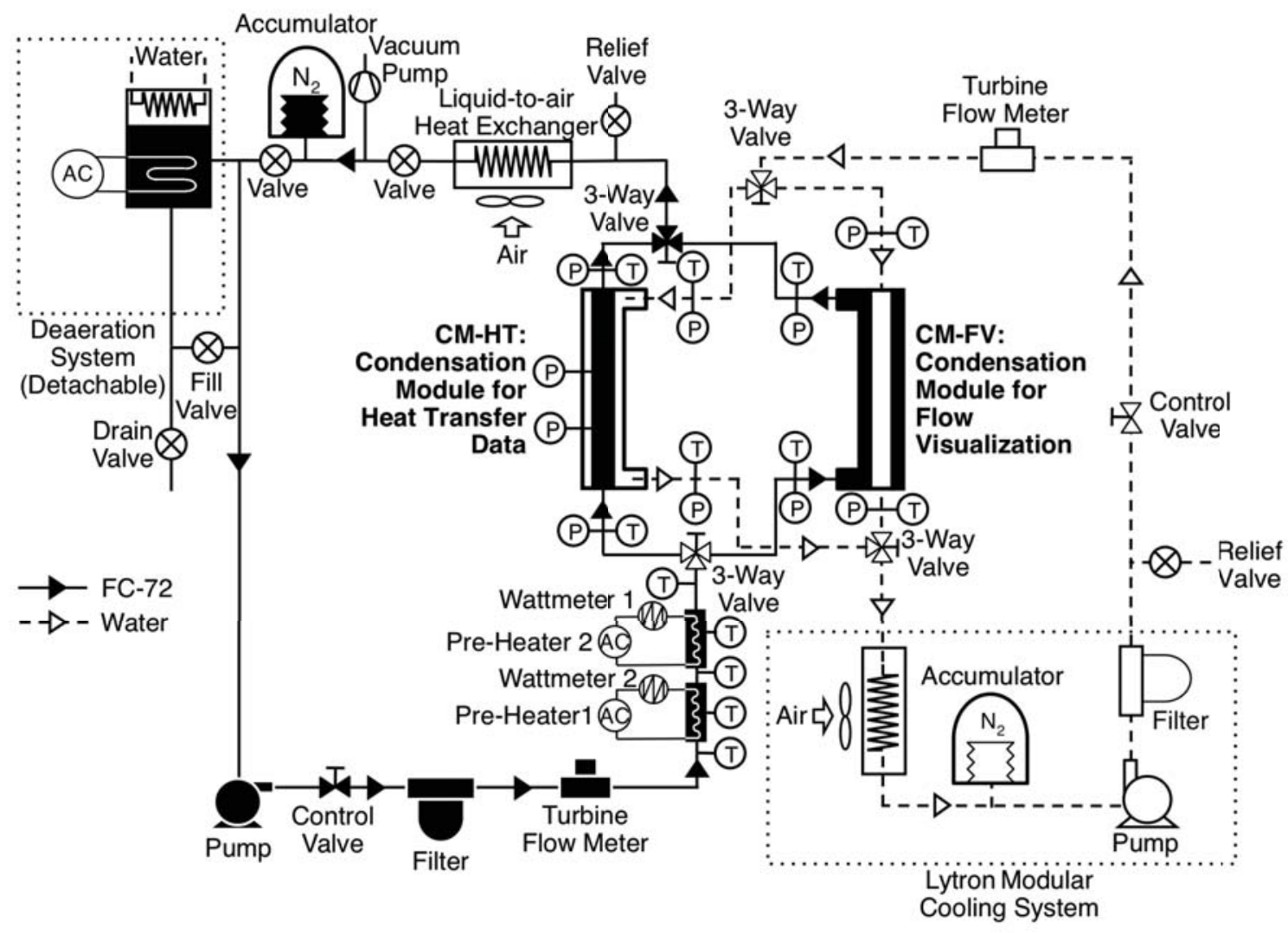

Figure 4 Schematic fo Flow Loop 
aid of a Lytron modular cooling system comprised of a positive displacement pump and a high-performance fan-cooled heat exchanger. The Lytron system is modified for the present study by incorporating a stainless steel reservoir and a Flexicraft Hydropad12 accumulator. The water flow rate is regulated with the aid of a control valve and measured by a Flow Technology Omniflo turbine flow meter. The water exiting the test module is returned to the Lytron system where it is cooled back to near-ambient temperature.

Figure 4 shows the condensation facility also includes a detachable fluid reservoir that is used to deaerate the FC-72 before initiating the tests. The deaeration is achieved by boiling FC-72 liquid in the reservoir using four immersion heaters for $30 \mathrm{~min}$. A water-cooled condenser coil atop the reservoir captures most of the vapor by condensation, while allowing non-condensable gases to escape to the ambient. The water is circulated by a Lytron system consisting of a reservoir, pump and water-to-air fan-cooled heat exchanger. Following the deaeration procedure, the reservoir is sealed off and allowed to cool down to ambient temperature before the fluid is charged into the FC-72 sub-loop. The deaeration reservoir is then detached from the condensation facility before the aircraft takes off. The deaeration procedure is repeated every two days of testing to maintain high FC-72 purity.

All pressures in the condensation facility are measured using Honeywell STJE absolute pressure transducers with an accuracy of $\pm 0.05 \%$, and visually verified with Wika pressure gauges having an accuracy of $\pm 1 \%$. Temperatures are measured with type-T thermocouples having an uncertainty of $\pm 0.4{ }^{\circ} \mathrm{C}$. Both Flow Technology Omniflo turbine flow meters used to measure the flow rates of $\mathrm{FC}-72$ and water have accuracies of $\pm 0.25 \%$. The Yokogawa WT200 and WT210 power meters used to measure the electrical power input to the first and second pre-heaters possess accuracies of $\pm 0.2 \%$ and $\pm 0.1 \%$, respectively. The overall uncertainty in determining the condensation heat transfer coefficient is $\pm 8.88 \%$.

\section{Packaging and Structural Support of Test Facility}

To facilitate ease of transport to, and mounting inside the aircraft, the condensation facility consists of three separately packaged rigs: (a) main condensation rig, (b) water conditioning rig, and (c) deaeration rig, as depicted in Fig. 5.

The condensation rig is the main part of the facility, containing the two condensation modules, entire FC-72 sub-loop, and most of the controls, cameras and data acquisition equipment. These components are mounted onto a rigid rectangular rack constructed of extruded aluminum members and framing system manufactured by $80 / 20$ Inc. The rack is fastened to the aircraft floor using $12-3 / 8$ bolts. To support the heavy weight of the condensation rig $(576 \mathrm{~kg})$ under aircraft emergency loads, structural analysis software is used for both the rack design and attachment to the aircraft floor. Structural integrity of the rack is further verified by actual $9-g_{e}$ pull-tests that are conducted on the components on the rack prior to the aircraft experiments. A key contributor to the weight of the condensation rig is the large FC-72 accumulator, which is fitted in a custom heavy mounting fixture at the lowest level of the condensation rig to enhance structural stability and reduce lateral stresses during parabolic flight. The large size of the FC-72 accumulator is necessitated by the large fluid volume changes in the FC-72 sub-loop.

All pressure and flow rate display panels are located on the front of the condensation rig. Also located on the front is a laptop for data acquisition (DAQ), potentiometers, FC-72 control valve, and pump controller. This arrangement facilitates convenient

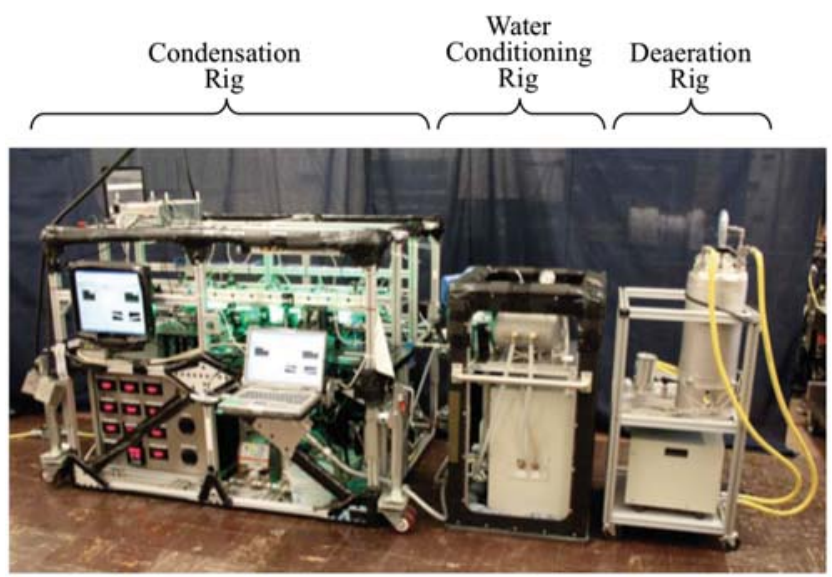

Fig. 5 Photo of Three Rigs of Test Facility

viewing of instrument panels and system control by the lead operator of the facility during the aircraft microgravity experiments from a single stationary location to avoid any motion sickness. A second monitor is mounted in the top left quadrant of the rack to show the DAQ laptop display so that the operator can view the operating conditions with minimal movement. During the first flight week, the condensation rig contained a total of three laptops, which included two located on the sides to download images from two separate high-speed video cameras simultaneously during the $\mu g$ period of the parabola when using CM-FV. During the second flight week, the condensation module contained three high-speed cameras. One high-speed camera was located at the CM-FV inlet, another at the middle, and the third at the outlet. Each high-speed camera required its own laptop plus the DAQ laptop for triggering the cameras, so a total of four laptops were used during the second flight week when CM-FV was operated.

During the second flight week, three different cameras all located in the condensation rig, are used for flow visualization; two are high-speed and the third conventional speed. A single button is used to trigger both high speed cameras simultaneously during the microgravity experiments. This button is located next to the DAQ laptop to enable the lead operator to trigger the cameras while viewing the aircraft's acceleration data. The standard $29.97 \mathrm{fps}$ camera was replaced by a third high-speed camera that became available for use during the second flight week.

The water conditioning rig contains the Lytron modular cooling system (mainly water pump and fan-cooled heat exchanger) in addition to a filter, stainless steel reservoir and water accumulator. The water conditioning rig is connected to the condensation rig using flexible hoses fitted with quick disconnect couplers to facilitate fast connection and disassembly before and after the aircraft experiments, respectively.

The deaeration rig contains a reservoir fitted with immersion heaters and a condensing coil. As discussed earlier, this rig is detached from the facility after deaeration and not boarded during the aircraft experiments.

\section{Test Procedure}

The reduced gravity environment is achieved by flying a modified Boeing 727 jet (ZGC B-727) in a series of parabolic maneuvers in two separate campaigns, each consisting of four days of flight. Figures 6(a) and 6(b) show, respectively, the parabolic flight trajectory and local heat transfer coefficient at $z=310 \mathrm{~mm}$ from the inlet of condensation length with gravity change. Each parabola is initiated with a $60-\mathrm{s}, 1.8-g$ (hyper-g) "pull-up," 

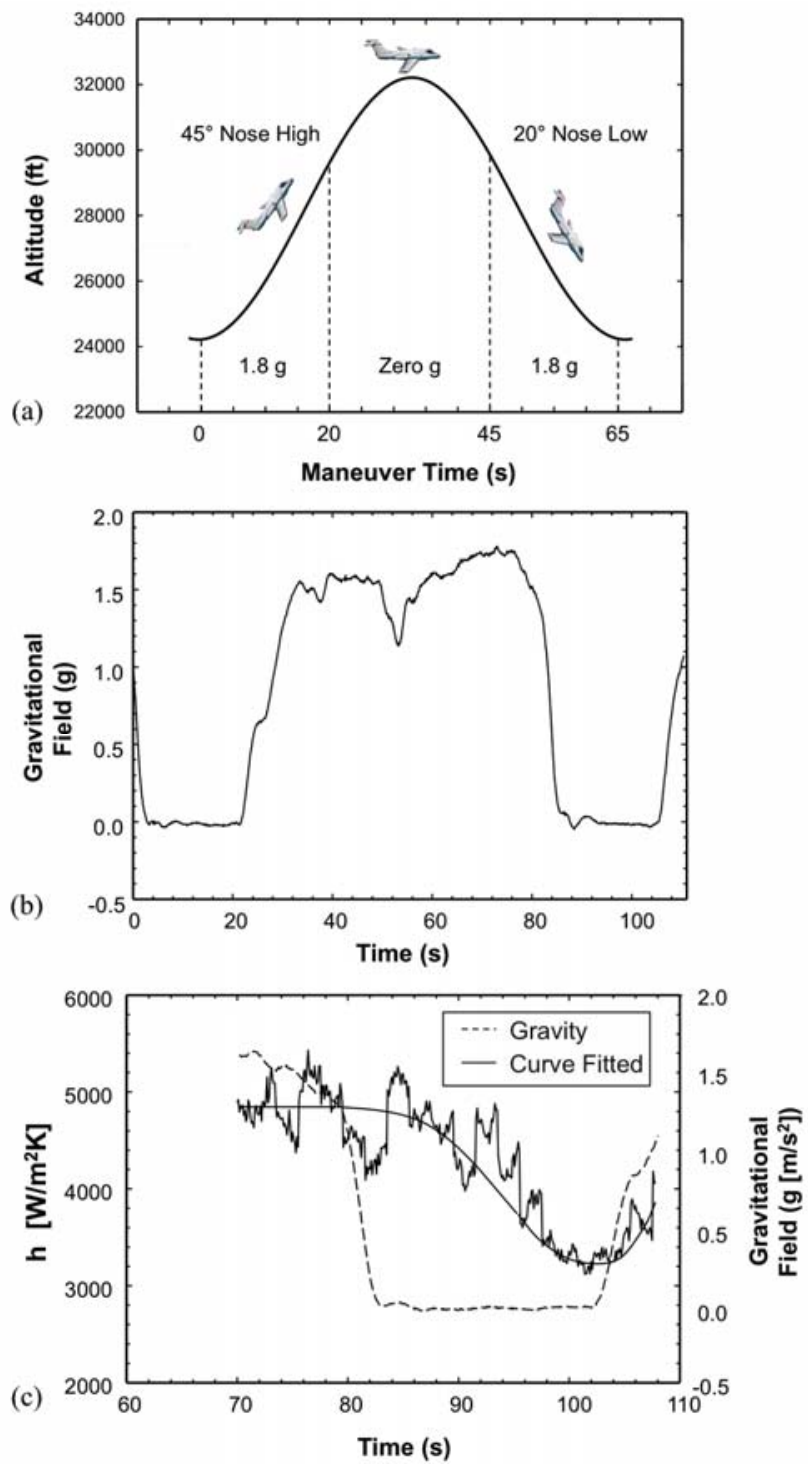

Fig. 6 (a) Parabolic Flight Trajectory, (b) Gravity Profile and (c) Local Heat Transfer Coefficient at $z=310 \mathrm{~mm}$ with Gravity Profile.

followed by approximately $17 \mathrm{~s}$ of $\mu g$, and terminated with a $1.8-g$ (hyper- $g$ ) "pullout" before initiating a pull-up for the next parabola. The pullout plus pull-up duration between consecutive $\mu g$ periods is about $40 \mathrm{~s}$. A typical day of testing consists of a twohour flight comprised of 40 parabolic maneuvers, with each parabola lasting about $17 \mathrm{~s}$, and every 10 parabolas separated by a 5-min aircraft turnaround break.

Due to large size and operational complexity of the condensation facility, and need to minimize operator movement that may induce motion sickness (especially during hyper- $g$ periods, when operating conditions are set for the subsequent $\mu g$ period), a total of five flight operators are needed. Three operators sit in front of the condensation rig to set operating conditions such as flow rates of FC-72 and water, and power input to the two FC72 pre-heaters, while observing data using Labview software. Operating conditions for a given $\mu g$ period are set during the preceding pull-up. All temperature, pressure, flow rate and power input data are recorded during the entire $\mu g$ period using two data
Table 2 Operating Conditions for Condensation Modules CM-HT and CM-FV

\begin{tabular}{|c|c|c|c|c|c|c|}
\hline & $\begin{array}{c}\dot{m}_{F C} \\
{[\mathrm{~g} / \mathrm{s}]}\end{array}$ & $\begin{array}{c}\dot{m}_{\text {water }} \\
{[\mathrm{g} / \mathrm{s}]}\end{array}$ & $\begin{array}{c}T_{F C \text {.in }} \\
{\left[{ }^{\circ} \mathrm{C}\right]}\end{array}$ & $\begin{array}{c}P_{F C \text {. in }} \\
{[\mathrm{kPa}]}\end{array}$ & $\begin{array}{c}\Delta T_{w} \\
{\left[{ }^{\circ} \mathrm{C}\right]}\end{array}$ & $R e_{\text {Mlm.out }}$ \\
\hline Max. & 15.8 & 24.8 & 63.4 & 126 & 12.7 & 3096 \\
\hline Min. & 2.4 & 2.4 & 60.0 & 114 & 4.6 & 831 \\
\hline
\end{tabular}

acquisition systems, NI SCXI-1000 and NI USB 6259. The fourth operator sits to the left of the main condensation rig to download video records during hyper-g periods. To the right of the condensation rig, the fifth operator manipulates the water conditioning rig and helps download high-speed video records.

Since only one of the condensation modules could be tested at a given time, the entire flight day is dedicated to either amassing heat transfer data using CM-HT or performing flow visualization experiments using CM-FV. Table 2 shows a test matrix of 40 operating conditions that are attempted with both modules. Because of concerns over possible overheating of the surface of the second pre-heater and PFiB production due to FC-72 breakdown, the quality of FC-72 at the inlet to the desired test module is set as close to but below unity, such that the inlet always contained some liquid. Once an operating condition is set, it is maintained for two consecutive parabolas, including the hyper-g period, to assess both repeatability and attainment of steady state conditions. The entire test matrix is re-tested on different flight days to check for repeatability.

Because of the short duration of microgravity, about $17 \mathrm{~s}$, during a parabola, there is considerable concern over the ability to reach steady state conditions. To achieve steady state with confidence, the thermocouples and pressure transducers are chosen to provide response times that are smaller than 0.01 and $0.05 \mathrm{~s}$, respectively, which are much smaller than the period of a single parabola. Of a total of 67 tests performed with CM-HT, only 42 selected cases used for analysis of the condensation heat transfer coefficient after monitoring temperatures and corresponding heat transfer coefficients with respect to gravity and time change. All 42 cases yielded steady state temperature and heat transfer coefficient data during the last 1-2 s of the parabola.

The operating conditions for the study are as follows: FC-72 mass velocities of $G=129.0-340.5 \mathrm{~kg} / \mathrm{m}^{2} \mathrm{~s}, \mathrm{FC}-72$ inlet pressures of $P_{F C \text {, in }}=113.7-126.3 \mathrm{kPa}(16.5-18.3$ psia $), \mathrm{FC}-72$ saturation temperatures of $T_{\text {sat }}=60.0-63.4^{\circ} \mathrm{C}, \mathrm{FC}-72$ inlet thermodynamic equilibrium qualities of $x_{e \text { in }}$ up to 0.98 , water mass velocities of $G_{w}$ $=86.7-321.4 \mathrm{~kg} / \mathrm{m}^{2} \mathrm{~s}$, water inlet pressures of $P_{w, \text { in }}=120.0-$ $127.0 \mathrm{kPa}(17.4-18.4 \mathrm{psia})$, and water inlet temperatures of $T_{w, i n}=$ $24.4-27.4^{\circ} \mathrm{C}$. A maximum electrical power input to the two $\mathrm{FC}$ 72 pre-heaters of $1490.4 \mathrm{~W}$ yielded FC-72 film Reynolds numbers as high as $R e_{f i l m}=3096.3$.

\section{Photographic Techiniques}

Using CM-FV, three different cameras are used to record images of the FC-72 condensate film at three axial locations along the condensation length: inlet, middle and outlet. A high-speed Phantom camera is positioned to view inlet, where it captures a 1-s record during each parabola at 4000 frames per second (fps) with a resolution of $512 \times 256$ pixels. Positioned in the middle is a highspeed Photron FASTCAM-Ultima APX camera, which captures a 0.75 -s record per parabola at 4000 fps with $1024 \times 128$-pixel resolution. During the first flight week, a third Pulnix CCD camera captures continuous images of the outlet region during the entire flight period at $29.97 \mathrm{fps}$ with $640 \times 480$-pixel resolution, 

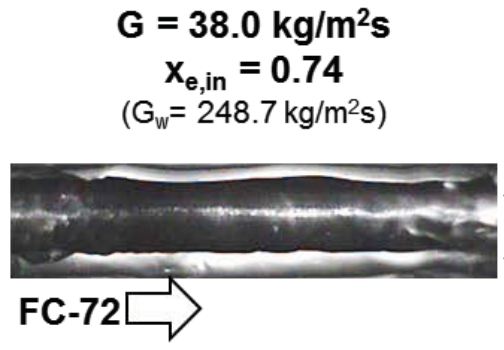

$$
\begin{gathered}
\mathbf{G}=63.8 \mathrm{~kg} / \mathrm{m}^{2} \mathrm{~s} \\
X_{\mathrm{e}, \mathrm{in}}=0.59 \\
\left(\mathrm{G}_{\mathrm{w}}=248.5 \mathrm{~kg} / \mathrm{m}^{2} \mathrm{~s}\right)
\end{gathered}
$$

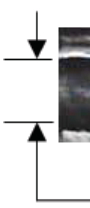

$$
\begin{gathered}
\mathbf{G}=128.8 \mathrm{~kg} / \mathrm{m}^{2} \mathrm{~s} \\
x_{\mathrm{e}, \mathrm{in}}=\mathbf{0 . 4 1} \\
\left(G_{\mathrm{w}}=272.8 \mathrm{~kg} / \mathrm{m}^{2} \mathrm{~s}\right)
\end{gathered}
$$

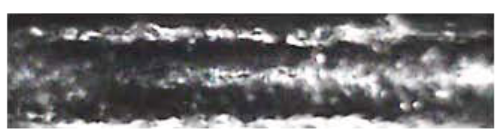

(a)

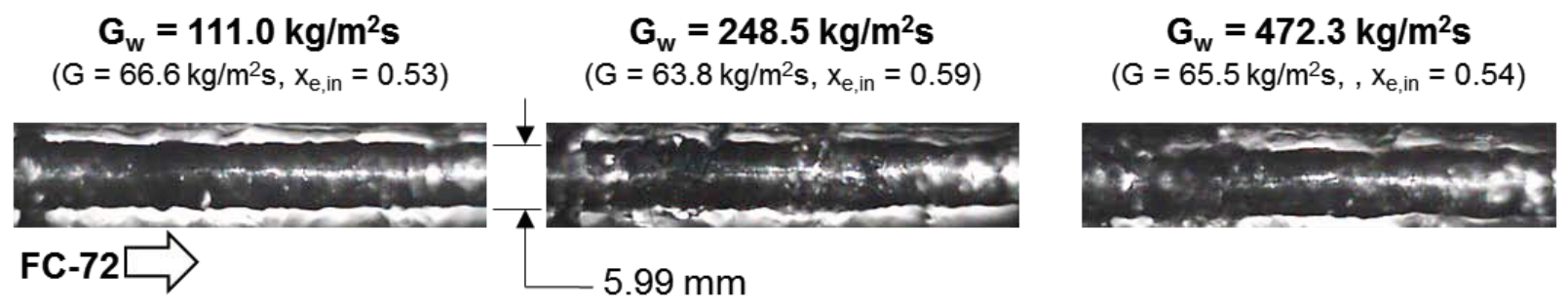

(b)

Fig. 7 Images of Condensation Film on Outer Surface of Central Stainless Steel Tube of CM-FV in Microgravity for (a) Three FC-72 Mass Velocities at Nearly Constant Water Flow Rate, and (b) Three Water Flow Rates at Nearly Constant FC-72 Flow Rate. The Images are 40-mm Long and Centered at $z=5.8 \mathrm{~cm}$ from the Inlet of the Condensation Length.

which are recorded on a Sony GV-D1000 walkman VCR. Four green LED light sources provide appropriate brightness for the two high-speed cameras.

The flow visualization experiments were performed using CM-FV during 120 parabolas spanning a total of 3 flight days from two separate campaign weeks.

\section{RESULTS}

\section{Flow Visualization Results}

Figure 7(a) shows images of the FC-72 condensation film along the outer surface of the stainless steel tube inside CM-FV for three different FC-72 mass velocities of $G=38.0,63.8$ and 128.8 $\mathrm{kg} / \mathrm{m}^{2} \mathrm{~s}$ and water mass velocities in the range of $G_{w}=248.5-$ $272.8 \mathrm{~kg} / \mathrm{m}^{2} \mathrm{~s}$. These images, which were captures by the Phantom 5 video camera at $4000 \mathrm{fps}$, are $40-\mathrm{mm}$ long and centered $5.8 \mathrm{~cm}$ from the inlet to the condensation length. Notice how the film is laminar and mostly smooth for the lowest value of $G=38.0$ $\mathrm{kg} / \mathrm{m}^{2} \mathrm{~s}$. At $G=63.8 \mathrm{~kg} / \mathrm{m}^{2} \mathrm{~s}$, the film appears to turn wavylaminar, with the interface displaying appreciable interfacial

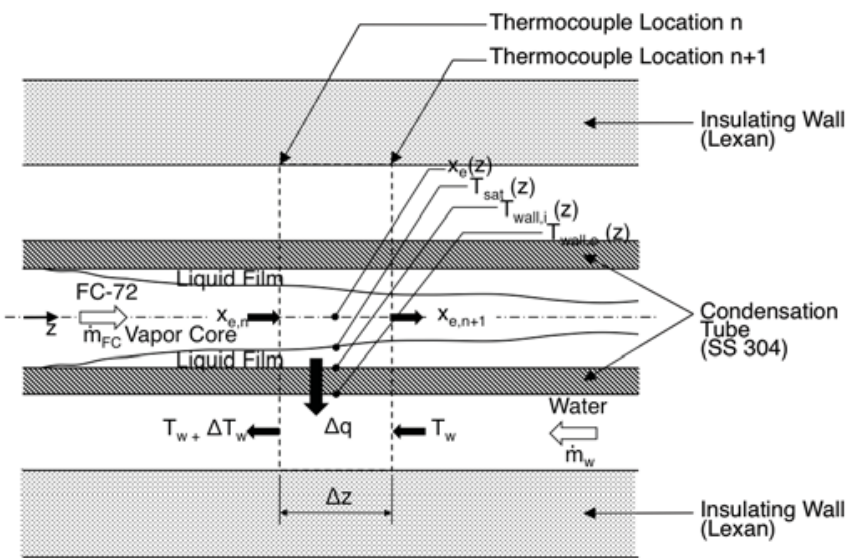

Fig. 8 Thermal Model Used to Determine the Axial Variations of Water Temperature, $T_{w}$, Outer Wall Temperature, $T_{\text {wall }, o}$, and FC-72 Quality, $x_{e}$. waviness. The flow is both wavy and turbulent at $G=128.8$ $\mathrm{kg} / \mathrm{m}^{2} \mathrm{~s}$, and the interfacial waviness far more complex than at $G=$ $63.8 \mathrm{~kg} / \mathrm{m}^{2} \mathrm{~s}$, exhibiting both small ripples and fast moving large waves.

Figure 7(b) shows images of the condensation film for three different water mass velocities of $G_{w}=111.0,248.5$ and 472.3 $\mathrm{kg} / \mathrm{m}^{2} \mathrm{~s}$ and FC-72 mass velocities in the range of $G=63.8-66.6$ $\mathrm{kg} / \mathrm{m}^{2} \mathrm{~s}$. For all three cases, the film appears wavy-laminar similar to that in the middle image of Fig. 7(a) corresponding to $G=63.8$ $\mathrm{kg} / \mathrm{m}^{2} \mathrm{~s}$. More importantly, increasing $G_{w}$ for a fairly constant $G$ does not appear to have a significant effect on the film flow behavior. Overall, Figs. 7(a) and 7(b) prove that the motion of the condensate film is far more sensitive to the mass velocity of FC-72 than that of the cooling water.

\section{Determination of Local Condensation Heat Transfer Coefficient}

As shown in Fig. 2(b), the temperatures of water and outer wall of the stainless steel tube are measured at discrete axial thermocouple locations along the condensation length of CM-HT. As illustrated in Fig. 8, the water temperature, $T_{w}(z)$, and outer wall temperature, $T_{\text {wall,o }}(z)$, of the stainless steel tube at the midpoint between axial measurement stations $n$ and $n+1$ are determined from curve fits to the measured water and wall temperatures. The heat transfer rate, $\Delta q$, from the FC-72 to the water over the axial span $\Delta z$ between the two thermocouple stations is equal to the corresponding increase in sensible heat of water, which is based on the temperature rise $\Delta T_{w}$ measured between the two stations. Accounting for thermal resistance across the tube wall, the inner wall temperature, $T_{\text {wall, }}$, is determined from the relation

$$
\Delta q=\dot{m}_{w} c_{p, w} \Delta T_{w}=\frac{T_{\text {wall }, i}-T_{\text {wall }, o}}{\frac{\ln \left(D_{o} / D_{i}\right)}{2 \pi k_{s s} \Delta z}} .
$$

Next, the FC-72 condensation heat transfer coefficient, $h(z)$, at the midpoint between stations $n$ and $n+1$ is determined from the relation 

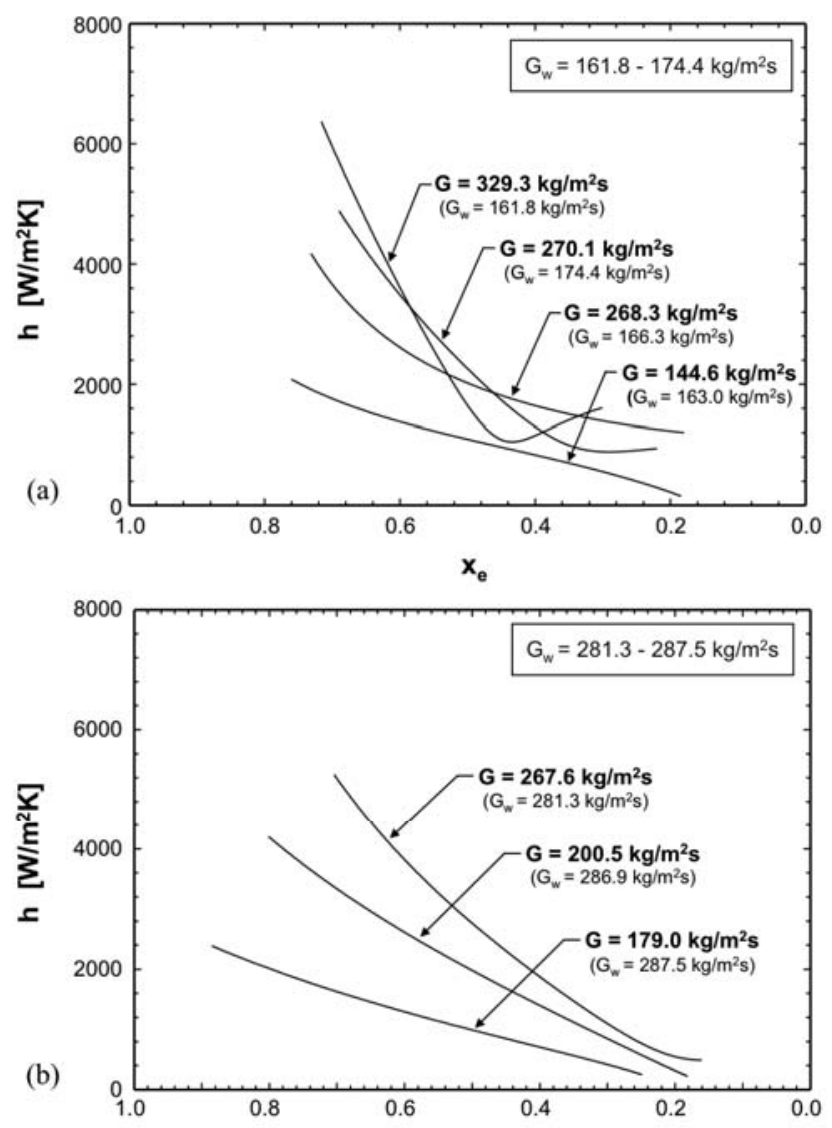

Fig. 9 Variation of Experiméntally-Determined Local Condensation Heat Transfer Coefficient with Thermodynamic Equilibrium Quality of FC-72 for Different FC-72 Mass Velocities and Water Mass Velocities of (a) $G_{w}=161.8-174.4 \mathrm{~kg} / \mathrm{m}^{2} \mathrm{~s}$ and (b) $G_{w}=281.3-287.5$ $\mathbf{k g} / \mathrm{m}^{2} \mathrm{~s}$

$$
\begin{aligned}
h(z) & =\frac{\Delta q}{\left(\pi D_{i} \Delta z\right)\left[T_{\text {sat }}(z)-T_{\text {wall }, i}(z)\right]} \\
& =\frac{\dot{m}_{w} c_{p, w} \Delta T_{w}}{\left(\pi D_{i} \Delta z\right)\left[T_{\text {sat }}(z)-T_{\text {wall }, i}(z)\right]} .
\end{aligned}
$$

Because pressure drop along the condensation length is quite small $(<2.93 \mathrm{kPa})$, Tsat and FC-72 liquid and vapor properties are nearly constant, and are based in the above calculations on the average of the measured inlet and outlet pressures.

Heat transfer calculations between consecutive axial thermocouple stations showed that axial conduction along the tube wall account for less than $0.1 \%$ of the heat conducted in the radial direction and used for data reduction per Eqs. (1) and (2).

The quality of FC-72 at the inlet to the condensation tube, $x_{e, i n}$, is calculated from the measured temperature at the inlet to the upstream pre-heater and electrical power input to the two preheaters. Marching forward along the condensation length, the thermodynamic equilibrium quality, $x_{e}(z)$, at the midpoint between stations $n$ and $n+1$ is obtained by accounting for all heat input between 0 and $z$ according to

$$
x_{e}(z)=x_{e, i n}-\frac{\sum_{j=1}^{n} \Delta q_{j}+\frac{\Delta q_{n+1}}{2}}{h_{f g}} .
$$

The flow rate of liquid FC-72, $\dot{m}_{\text {film }}$, in the annular film is finite at $z=0$ and its local value is determined from the relation

$$
\dot{m}_{f i l m}=\left(1-x_{e}\right) \dot{m}_{F C} .
$$

\section{Heat Transfer Results}

Figure 9(a) shows the variations of local condensation heat transfer coefficient, $\mathrm{h}$, with thermodynamic equilibrium quality for four FC-72 mass velocities of $G=144.6,268.3,270.1$ and 329.3 $\mathrm{kg} / \mathrm{m}^{2} \mathrm{~s}$ at water mass velocities in the range of $G_{w}=161.8-174.4$ $\mathrm{kg} / \mathrm{m}^{2} \mathrm{~s}$. The heat transfer coefficient is highest for high quality values near the inlet, where the film is thinnest. Gradual thickening of the film along the inner tube of CM-HT causes a gradual decrease in the heat transfer coefficient with decreasing quality. Near the inlet, the film is mostly laminar and the condensation heat transfer dominated by conduction across the film, which explains the axial decrease in the heat transfer coefficient. Figure 9(a) shows the heat transfer coefficient near the inlet increases with increasing $G$, a trend that can be explained by thinning of the film at high $G$ because of the higher vapor shear, which reduces thermal resistance across the film. Because of the axial increase in film thickness, the condensation heat transfer coefficient is shown decreasing monotonically along the tube for the two lowest $G$ values. However, there is a minimum in the axial variation of $h$ for the two highest $G$ values. Downstream from the minimum, $h$ begins to increase axially until the end of the condensation length. Notice that this downstream increase is more pronounced for the highest mass velocity of $G=329.3 \mathrm{~kg} / \mathrm{m}^{2} \mathrm{~s}$. Two plausible reasons for the minimum and downstream increase in $\mathrm{h}$ are interfacial waves and turbulent eddies. The interfacial waves, which amplify axially along the tube, increase the mean film velocity, thereby decreasing the film thickness. Waves also induce mixing within the film. Turbulent eddies intensify along the tube, which enhances the condensation heat transfer coefficient, potentially overcoming any conduction effects.

Figure 9(b) shows the variations of $h$ with thermodynamic equilibrium quality for three FC-72 mass velocities of $G=179.0$, 200.5 and $267.6 \mathrm{~kg} / \mathrm{m}^{2} \mathrm{~s}$ at water mass velocities in the range of $G_{w}$ $=281.3-287.5 \mathrm{~kg} / \mathrm{m}^{2} \mathrm{~s}$. The direction of decreasing quality is representative of axial location along the condensation length. The $G$ values in this plot are below the two highest $G$ values in Fig. 9(a) that produced a minimum as discussed above. Here, the axial variation of $\mathrm{h}$ is strictly monotonic, with the highest FC-72 mass velocity of $G=267.6 \mathrm{~kg} / \mathrm{m}^{2}$ s yielding the highest $h$ values.

Figures 10(a) - 10(d) show variations of the local condensation heat transfer coefficient with thermodynamic equilibrium quality for different water mass velocities but fairly similar FC-72 mass velocities. In each of these figures, corresponding to constant $G$, the condensation heat transfer coefficient for each water mass velocity, $G_{w}$, decreases along the condensation length as discussed earlier. However, the variations for different $G_{w}$ values are more clustered together compared to the variations for different $G$ values in Figs. 9(a) and 9(b). These trends demonstrate a far stronger dependence of $h$ on $G$ than on $G_{w}$

This trend is further manifest in Fig. 11, which shows the variation of the average condensation heat transfer coefficient, $\bar{h}$ with water mass velocity, $G_{w}$, for three different FC-72 mass velocities. This is the heat transfer coefficient averaged over the condensation length. Here, experimental data corresponding to fairly similar inlet qualities $\left(x_{e}=0.69-0.83\right)$ are used. Figure 11 shows increases appreciably with increasing $G$, but it is only mildly influenced by $G_{w}$. It should be noted that the poor sensitivity of $\bar{h}$ to $G_{w}$ is a result of the relatively high $G_{w}$ values 

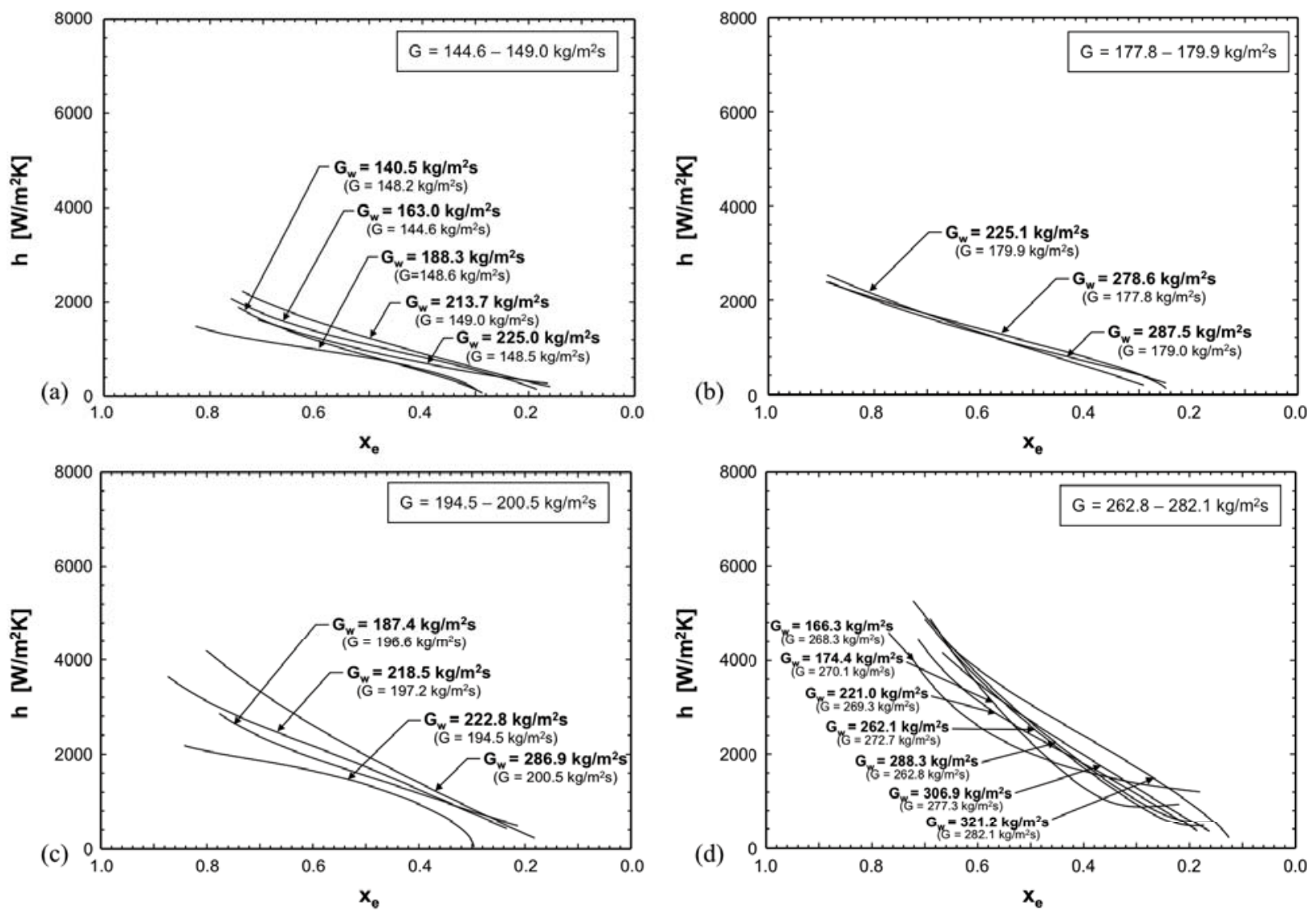

Fig. 10 Variation of experimentally-determined local condensation heat transfer coefficient with thermodynamic equilibrium quality of FC-72 for different water mass velocities and FC-72 mass velocities of (a) $G=144.6-149.0$ $\mathrm{kg} / \mathrm{m}^{2} \mathrm{~s}$, (b) $G=177.8-179.9 \mathrm{~kg} / \mathrm{m}^{2} \mathrm{~s}$, (c) $G=194.5-200.5 \mathrm{~kg} / \mathrm{m}^{2} \mathrm{~s}$, and (d) $G=262.8-282.1 \mathrm{~kg} / \mathrm{m}^{2} \mathrm{~s}$.

used in this study. Using high $G_{w}$ values is intended to achieve low waterside resistances in pursuit of better accuracy in determining the FC-72 heat transfer coefficient. It is not apparent from the present results if the poor sensitivity of $\bar{h}$ to $G_{w}$ is prevalent for low $G_{w}$ values as well.

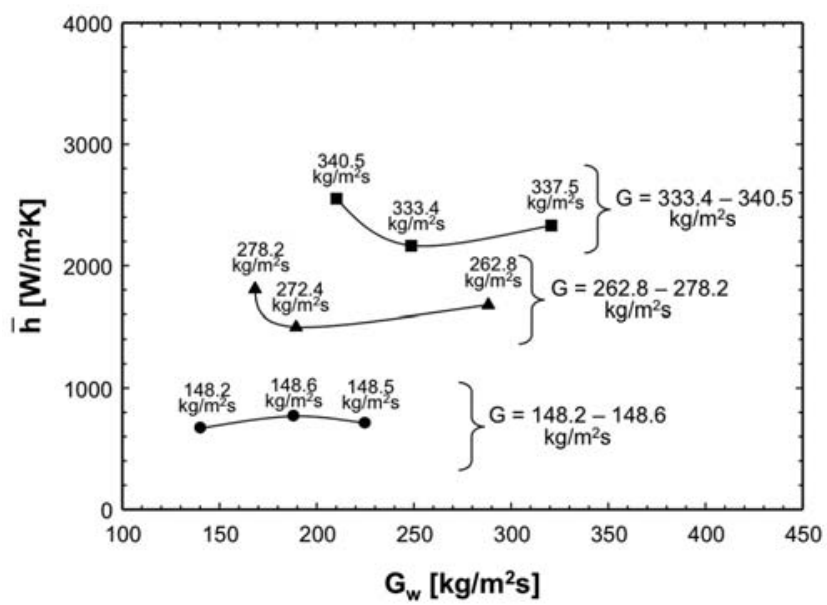

Fig. 11 Variation of Experimentally-Determined Average Condensation Heat Transfer Coefficient with Water Mass Velocity for Different FC-72 Mass Velocities.

\section{Assessment of Heat Transfer Correlations}

Figure 12 compares the present $\mu g$ data to predictions of seven popular correlations [20,23-28] for the condensation heat transfer coefficient that are detailed in Table 3. Shown are comparisons for the heat transfer coefficient averaged over the entire condensation length, along with the corresponding mean absolute error, which is defined as

$$
M A E=\frac{1}{N} \sum\left|\frac{\bar{h}_{\text {pred }}-\bar{h}_{\exp }}{\bar{h}_{\exp }}\right| .
$$

Figure 12 shows the MAE for the individual correlations varies from $21.8 \%$ for the recent $\mathrm{Kim}$ and Mudawar correlation [20] to $44.4 \%$ for the Dobson and Chato correlation [26].

Table 4 provides additional details concerning the predictive capabilities of the individual correlations in terms of percentage of predictions that are within $\pm 30 \%$ of the data. This percentage ranges from $38.5 \%$ for the Koyama et al. correlation [28] to $69.2 \%$ for the Kim and Mudawar correlation [20], providing further proof of the superior predictive accuracy of the latter. 
Table 3 Condensation Heat Transfer Correlations for Annular Flow.

\begin{tabular}{|c|c|c|}
\hline & Correlation & Remarks \\
\hline $\begin{array}{l}\text { Akers et al. } \\
\quad(1958)\end{array}$ & $\begin{array}{l}\frac{h D_{h}}{k_{f}}=0.0265 \operatorname{Re}_{e q}^{0.8} \operatorname{Pr}_{f}^{1 / 3} \text { for } \operatorname{Re}_{e q}>50,000 \\
\frac{h D_{h}}{k_{f}}=5.035 \operatorname{Re}_{e q}^{1 / 3} \operatorname{Pr}_{f}^{1 / 3} \text { for } \operatorname{Re}_{e q} \leq 50,000\end{array}$ & $\begin{array}{l}\operatorname{Re}_{e q}=G\left[(1-x)+x\left(\frac{\rho_{f}}{\rho_{g}}\right)^{1 / 2}\right] \frac{D_{h}}{\mu_{f}} \\
x_{e} \text { is used for } x \text { in comparison }\end{array}$ \\
\hline $\begin{array}{c}\text { Cavallini and } \\
\text { Zecchin (1974) }\end{array}$ & $\frac{h D_{h}}{k_{f}}=0.05\left[\operatorname{Re}_{g}\left(\frac{\mu_{g}}{\mu_{f}}\right)\left(\frac{\rho_{f}}{\rho_{g}}\right)^{0.5}+\operatorname{Re}_{f}\right]^{0.8} \operatorname{Pr}_{f}^{0.33}$ & $\begin{array}{l}\quad \operatorname{Re}_{g}=\frac{G x D_{h}}{\mu_{g}}, \operatorname{Re}_{f}=\frac{G(1-x) D_{h}}{\mu_{f}} \\
x_{e} \text { is used for } x \text { in comparison }\end{array}$ \\
\hline Shah (1979) & $\frac{h D_{h}}{k_{f}}=0.023 \operatorname{Re}_{f o}^{0.8} \operatorname{Pr}_{f}^{0.4}\left[\left(1-x_{e}\right)^{0.8}+\frac{3.8 x^{0.76}\left(1-x_{e}\right)^{0.04}}{P_{R}^{0.38}}\right.$ & $\operatorname{Re}_{f o}=\frac{G D_{h}}{\mu_{f}}, P_{R}=\frac{P}{P_{\text {crit }}}$ \\
\hline $\begin{array}{l}\text { Dobson and } \\
\text { Chato (1998) }\end{array}$ & $\frac{h D_{h}}{k_{f}}=0.023 \operatorname{Re}_{f}^{0.8} \operatorname{Pr}_{f}^{0.4}\left[1+\frac{2.22}{X_{t t}^{0.89}}\right]$ & $\begin{array}{l}\quad X_{t t}=\left(\frac{\rho_{g}}{\rho_{f}}\right)^{0.5}\left(\frac{\mu_{f}}{\mu_{g}}\right)^{0.1}\left(\frac{1-x}{x}\right)^{0.9} \\
x_{c} \text { is used for } x \text { in comparison }\end{array}$ \\
\hline $\begin{array}{l}\text { Wang et al. } \\
\text { (2002) }\end{array}$ & $\frac{h D_{h}}{k_{f}}=0.0274 \operatorname{Pr}_{f} \operatorname{Re}_{f}^{0.6792} x^{0.2208}\left(\frac{1.376+8 X_{t t}^{1.655}}{X_{t t}^{2}}\right)^{0.5}$ & $x_{e}$ is used for $x$ in comparison \\
\hline $\begin{array}{l}\text { Koyama et al. } \\
\text { (2003) }\end{array}$ & $\frac{h D_{h}}{k_{f}}=0.0152\left(1+0.6 \operatorname{Pr}_{f}^{0.8}\right)\left(\frac{\phi_{g}}{X_{t}}\right) \operatorname{Re}_{f}^{0.77}$ & $\begin{array}{l}\quad \phi_{g}=1+21\left(1-e^{-0.319 D_{h}}\right) X_{t t}+X_{t t}^{2} \\
x_{e} \text { is used for } x \text { in comparison }\end{array}$ \\
\hline $\begin{array}{c}\text { Kim and } \\
\text { Mudawar (2012) }\end{array}$ & $\frac{h D_{h}}{k_{f}}=0.048 \operatorname{Re}_{f}^{0.69} \operatorname{Pr}_{f}^{0.34} \frac{\phi_{g}}{X_{t t}}$ & $\begin{array}{l}\qquad X_{t t}=\left(\frac{\mu_{f}}{\mu_{g}}\right)^{0.1}\left(\frac{1-x}{x}\right)^{0.9}\left(\frac{\rho_{g}}{\rho_{f}}\right)^{0.5} \\
\qquad \phi_{g}^{2}=1+C X+X^{2}, X^{2}=\frac{(d P / d z)_{f}}{(d P / d z)_{g}} \\
\text { Different correlations for } C \text { for different } \\
\text { laminar and turbulent liquid and vapor flow } \\
\text { states }\end{array}$ \\
\hline
\end{tabular}

The relative success of the Kim and Mudawar correlation, which shows the least MAE, can be attributed to the large database upon which it is based. Validated for tube diameters between 0.424 to $6.22 \mathrm{~mm}$, this correlation is derived from the world's most comprehensive condensation database consisting of 4,045 data points from 28 sources, which cover 17 working fluids and very broad ranges of geometrical and flow parameters. The database includes mass velocities from $G=53$ to $1,403 \mathrm{~kg} / \mathrm{m}^{2} \mathrm{~s}$, liquid-only Reynolds numbers from $R e_{\text {film }}=276$ to 89,798, qualities from $x_{e}=$ 0 to 1 , and reduced pressures from $P_{R}=0.04$ to 0.91 . The correlation method actually consists of two separate correlations, one for annular flows, which is used in Fig. 12, and the second for slug and bubbly flows.

Despite the relative success of the Kim and Mudawar

Table 4 Comparison of Experimental Data for Average Condensation Heat Transfer Coefficient with Predictions of Prior Condensation correlations.

\begin{tabular}{|c|c|c|c|c|c|c|c|}
\hline & $\begin{array}{c}\text { Akers } \\
\text { et al. } \\
(1958)\end{array}$ & $\begin{array}{c}\text { Cavallini } \\
\text { and Zecchin } \\
(1974)\end{array}$ & Shah & $\begin{array}{c}\text { Dobson } \\
\text { and } \\
\text { Chato } \\
(1979)\end{array}$ & $\begin{array}{c}\text { Wang } \\
\text { et al. } \\
(1998)\end{array}$ & $\begin{array}{c}\text { Koyama } \\
\text { et al. } \\
(2002)\end{array}$ & $\begin{array}{c}\text { Kim } \\
\text { and } \\
\text { Mudawar } \\
(2012)\end{array}$ \\
\hline MAE [\%] & 41.0 & 37.5 & 27.6 & 44.3 & 28.9 & 31.0 & 21.8 \\
\hline $\begin{array}{c}\text { Percentage of } \\
\text { Predictions within } \\
\pm 30 \% \text { of Data }\end{array}$ & 64.1 & 56.4 & 66.7 & 48.7 & 48.7 & 38.5 & 69.2 \\
\hline
\end{tabular}

correlation in predicting the present data, it is premature to draw definitive conclusions concerning the validity of $1-g_{e}$ correlations or models to $\mu g$ condensation. Clearly, using a very high $G$ is expected to preclude gravity effects in the important range of 0-1 $g_{e}$. Yet, from a practical point of view, this is by no means a desired solution for future space systems, given the strong impact of pumping power on system performance and efficiency. In fact, the ultimate goal is to identify the smallest $G$ that would ensure gravity independence. This will demand extensive testing at both $1 g_{e}$ and $\mu g$, which is a long-term goal of the present authors.

Future work must also be pursued to develop a theoretical model that can tackle the complex influences of interfacial waves and turbulent eddies. The important influence of waves has been demonstrated for adiabatic [29], sensibly heated [30-32] and evaporating [33] falling liquid films. A fundamental concern when modeling turbulence in films is the dampening of turbulent fluctuations near the vapor-liquid interface due to surface tension; failure to account for this influence can lead to substantial errors in predicting the condensation heat transfer coefficient [21]. Incorporating these important effects in a theoretical model will require sophisticated diagnostic techniques that can accurately measure condensate film thickness and characterize interfacial waves $[29,31,32,34]$. Further insight into modeling both fluid flow and heat transfer mechanisms is available from recent studies of condensation in 1 ge (e.g., $[35,36])$. 


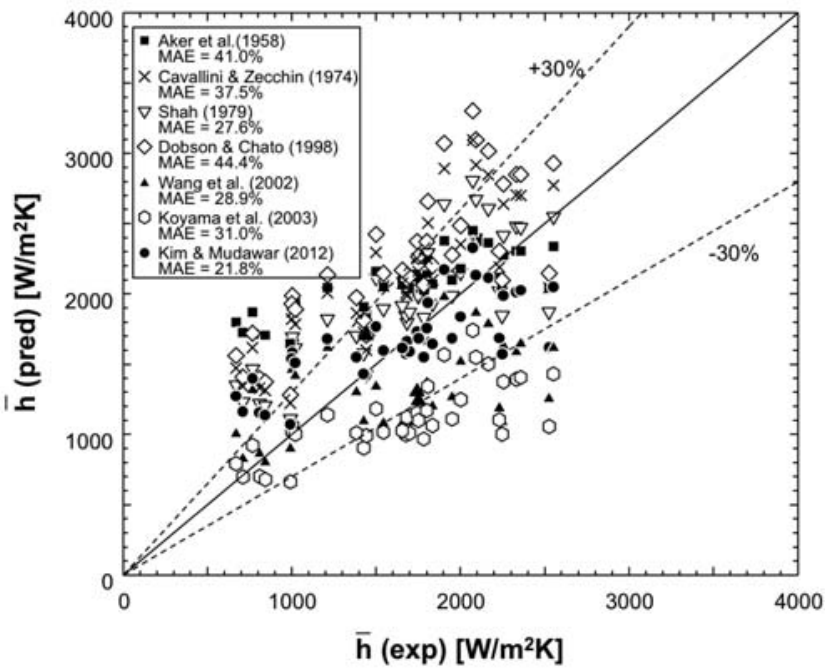

Fig. 12 Comparison of Experimentally-Determined Average Condensation Heat Transfer Coefficient with Predictions of Condensation Heat Transfer Correlation

\section{CONCULSION}

This study discussed the development of the Flow Boiling and Condensation Experiment (FBCE) for the International Space Station (ISS), and heat transfer results from parabolic flight experiments that simulated condensation of FC-72 in microgravity. The study also included high-speed video analysis of the condensate film's flow structure. The data were compared to predictions of seven popular correlations developed based on ground experiments for the condensation heat transfer coefficient. Key findings are as follows.

(a) Using two separate condensation modules, the proposed configuration of FBCE, including the FC-72 and water sub-loops and deaeration procedure, is successful in providing both detailed heat transfer measurements and video analysis of the condensate film. The condensation facility is well suited for microgravity testing, including the ability to achieve steady state between tests at different operating conditions over a very short period of time.

(b) The film flow is laminar and mostly smooth at low FC-72 mass velocities and high inlet quality. With increasing mass velocity, the flow first turns wavy-laminar, with the interface displaying appreciable interfacial waviness, and ultimately both wavy and turbulent, marred by both small ripples and fast moving large waves.

(c) For low FC-72 mass velocities with high inlet quality, the heat transfer coefficient is dominated by conduction across the film, and is highest near the inlet, where the film is thinnest, and decreases monotonically along the tube because of the increasing film thickness. But the heat transfer coefficient for high FC-72 mass velocities is enhanced downstream because of the combined benefits of turbulence and increased interfacial waviness.

(d) Previous one-ge correlations predict the average condensation heat transfer coefficient data with varying degrees of success, and a recent correlation by Kim and Mudawar [20] is identified for its superior predictive accuracy, evidenced by the least mean absolute error of $21.8 \%$ among the correlations tested. The success of this correlation is attributed to its reliance on a massive database, which includes 17 different working fluids and very broad ranges of all relevant flow and geometrical parameters.

\section{ACKNOWLEDGMENTS}

The authors are grateful for the support of the National Aeronautics and Space Administration (NASA) under grant no. NNX13AB01G. The authors also thank George Saad, David F. Chao, Robert L. Butcher, Alban D. Seigneur, Bruce J. Frankenfield, Paul A. Trimarchi, Richard A. Kelsch, Daniel J. Gotti, Chip Redding, Frank L. Kmiecik of the NASA Glenn Research Center for their technical assistance.

\section{Nomenclature}

$c_{p} \quad$ specific heat at constant pressure $(\mathrm{J} / \mathrm{kgK})$

$D_{h} \quad$ hydraulic diameter (m)

$D_{i} \quad$ inner diameter of condensation tube (m)

$D_{o} \quad$ outer diameter of condensation tube (m)

$G \quad$ mass velocity of FC-72 $(\mathrm{kg} / \mathrm{m} 2 \mathrm{~s})$

$g \quad$ gravitational acceleration $(\mathrm{m} / \mathrm{s} 2)$

$g_{e} \quad$ Earth's gravitational acceleration $(\mathrm{m} / \mathrm{s} 2)$

$G_{w} \quad$ mass velocity of water $(\mathrm{kg} / \mathrm{m} 2 \mathrm{~s})$

$h \quad$ heat transfer coefficient $(\mathrm{W} / \mathrm{m} 2 \mathrm{~K})$

$\bar{h} \quad$ average heat transfer coefficient $(\mathrm{W} / \mathrm{m} 2 \mathrm{~K})$

$h_{f g} \quad$ latent heat of vaporization $(\mathrm{J} / \mathrm{kg})$

$k$ thermal conductivity (W/m.K)

$\dot{m}$ mass flow rate $(\mathrm{kg} / \mathrm{s})$

$M A E \quad$ mean absolute error

$P \quad$ pressure $(\mathrm{N} / \mathrm{m} 2)$

$P_{\text {crit }} \quad$ critical pressure $(\mathrm{N} / \mathrm{m} 2)$

$P_{R} \quad$ reduced pressure

$\mathrm{Pr} \quad$ Prandtl number

$q \quad$ heat transfer rate (W)

Re Reynolds number

$T_{\text {sat }} \quad$ saturation temperature (K)

$W \quad$ outer channel width of condensation module CM-FV (m)

$X \quad$ Lockhart-Martinelli parameter

$x \quad$ vapor quality

$x_{e} \quad$ thermodynamic equilibrium quality

$z \quad$ stream-wise coordinate $(\mathrm{m})$

\section{Greek Symbols}

$\mu \quad$ dynamic viscosity (Ns/m2)

$\rho \quad$ density $(\mathrm{kg} / \mathrm{m} 3)$

$\sigma \quad$ surface tension $(\mathrm{N} / \mathrm{m})$

$\phi \quad$ two-phase multiplier

\section{Subscripts}

$\exp \quad$ experimental

$f \quad$ saturated liquid

FC $\quad$ FC-72

film liquid film

$g \quad$ saturated vapor

$i \quad$ inner surface of condensation tube

in inlet of condensation length

$o \quad$ outer surface of condensation tube

out outlet of condensation length

pred predicted

ss stainless steel

$t t \quad$ turbulent liquid-turbulent vapor

w water

wall wall

\section{REFERENCES}

[1] Ganapathi, G.B., Birur, G., Sunada E., and Miller, J., 2008, "Two Phase vs. Single Phase Thermal Loop Trades for Exploration Mission LAT II Architecture," SAE Paper 2008-01-1958. 
[2] Ganapathi, G.B., Birur, G., Tsuyuki G., and Krylo, R., 2004, "Mars Exploration Rover Heat Rejection System Performance Comparison of Ground and Flight Data," SAE Paper 2004-012413

[3] Chiaramonte, F.P. and Joshi, J.A., 2004, "Workshop on Critical Issues in Microgravity Fluids, Transport, and Reaction Processes in Advanced Human Support Technology - Final Report," NASA Report TM-2004-212940, Washington, D.C..

[4] National Research Council, 2011, "Recapturing a Future for Space Exploration: Life and Physical Sciences Research for a New Era," The National Academies Press, Washington, D.C..

[5] Anderson, T.M. and Mudawar, I., 1989, "Microelectronic Cooling by Enhanced Pool Boiling of a Dielectric Fluorocarbon Liquid," J HEAT TRANS - T ASME 111, pp. 752-759.

[6] Willingham, T.C. and Mudawar, I., 1992, "Forced-Convection Boiling and Critical Heat Flux from a Linear Array of Discrete Heat Sources," Int. J. Heat Mass Transfer 35, pp. 2879-2890.

[7] Monde, M. and Inoue, T., 1991, "Critical Heat Flux in Saturated Forced Convective Boiling on a Heated Disk with Multiple Impinging Jets," J HEAT TRANS - T ASME 113, pp. 722-727.

[8] Wadsworth, D.C. and Mudawar, I., 1992, "Enhancement of Single-Phase Heat Transfer and Critical Heat Flux from an UltraHigh-Flux-Source to a Rectangular Impinging Jet of Dielectric Liquid," J HEAT TRANS - T ASME 114, pp. 764-768.

[9] Johns, M.E. and Mudawar, I., 1996, "An Ultra-High Power Two-Phase Jet-Impingement Avionic Clamshell Module," J Electronic Packaging - T ASME 118, pp. 264-270.

[10] Lin, L. and Ponnappan, R., 2003, "Heat Transfer Characteristics of Spray cooling in a Closed Loop," Int. J. Heat Mass Transfer 46, pp. 3737-3746.

[11] Rybicki, J.R. and Mudawar, I., 2006, "Single-Phase and Two-Phase Cooling Characteristics of Upward-Facing and Downward-Facing Sprays," Int. J. Heat Mass Transfer 49, pp. 516.

[12] Webb, R.L., 1981, "The Evolution of Enhanced Surface Geometries for Nucleate Boiling," Heat Transfer Engng 2, pp. 4669.

[13] Khanikar, V., Mudawar, I., and Fisher, T., 2009, "Effects of Carbon Nanotube Coating on Flow Boiling in a Micro-Channel," Int. J. Heat Mass Transfer 52, pp. 3805-3817.

[14] Yan, Y.Y. and Lin, T.F., 1999, "Condensation Heat Transfer and Pressure Drop of Refrigerant R-134a in a Small Pipe," Int. J. Heat Mass Transfer 42, pp. 697-708.

[15] Baird, J.R., Fletcher, D.F., and Haynes, B.S., 2003, "Local Condensation Heat Transfer Rates in Fine Passages," Int. J. Heat Mass Transfer 46, pp. 4453-4466.

[16] Kim, N.H., Cho, J.P., Kim, J.O., and Youn, B., 2003, "Condensation Heat Transfer of R-22 and R-410A in Flat Aluminum Multi-Channel Tubes with or without Micro-Fins," Int. J. Refrigeration 26, pp. 830-839.

[17] Kim, S.M., Kim, J., and Mudawar, I., 2012, "Flow Condensation in Parallel Micro-Channels - Part 1: Experimental Results and Assessment of Pressure Drop Correlations," Int. J. Heat Mass Transfer 55, pp. 971-983.

[18] Kim, S.M. and Mudawar, I., 2012, "Flow Condensation in Parallel Micro-Channels - Part 2: Heat Transfer Results and Correlation Technique," Int. J. Heat Mass Transfer 55, pp. 984994.

[19] Kim, S.M. and Mudawar, I., 2012, "Universal Approach to Predicting Two-Phase Frictional Pressure Drop for Adiabatic and Condensing Mini/Micro-Channel Flows," Int. J. Heat Mass Transfer 55, pp. 3246-3261.
[20] Kim, S.M. and Mudawar, I., 2013, "Universal Approach to Predicting Heat Transfer Coefficient for Condensing Mini/MicroChannel Flows," Int. J. Heat Mass Transfer 56, pp. 238-250.

[21] Kim, S.M. and Mudawar, I., 2012, "Theoretical Model for Annular Flow Condensation in Rectangular Micro-Channels," Int. J. Heat Mass Transfer 55, pp. 958-970.

[22] Park, I., Kim, S.M., and Mudawar, I., 2013, "Experimental Measurement and Modeling of Downflow Condensation in a Circular Tube," Int. J. Heat Mass Transfer 57, pp. 567-581..

[23] Akers, W.W., Deans, H.A., and Crosser, O.K., 1958, "Condensing Heat Transfer within Horizontal Tubes," Chem. Eng. Prog. 54, pp. 89-90.

[24] Cavallini, A. and Zecchin, R., 1974, "A Dimensionless Correlation for Heat Transfer in Forced Convection Condensation," Proc. of the Fifth Int. Heat Transfer Conf. 3, pp. 309-313, Tokyo, Japan.

[25] Shah, M.M., 1979, "A General Correlation for Heat Transfer during Film Condensation Inside Pipes," Int. J. Heat Mass Transfer 22 , pp. $547-556$.

[26] Dobson, M. and Chato, J., 1998, "Condensation in Smooth Horizontal Tubes," J HEAT TRANS - T ASME 120, pp. 193-213.

[27] Wang, W.W., Radcliff, T., and Christensen, R.N., 2002, “A Condensation Heat Transfer Correlation for Millimeter-Scale Tubing with Flow Regime Transition,” Exp. Therm. Fluid Sci. 26, pp. 473-485.

[28] Koyama, S., Kuwahara, K., Nakashita, K., and Yamamoto, K., 2003, "An Experimental study on Condensation of Refrigerant R134a in a Multi-Port Extruded Tube," Int. J. Refrigeration 24, pp. 425-432.

[29] Mudawar, I. and Houpt, R.A., 1993, "Measurement of Mass and Momentum Transport in Wavy-Laminar Falling Liquid Films," Int. J. Heat Mass Transfer 36, pp. 4151-4162.

[30] Shmerler, J.A. and Mudawar, I., 1988, "Local Heat Transfer Coefficient in Wavy Free-Falling Turbulent Liquid Films undergoing Uniform Sensible Heating," Int. J. Heat Mass Transfer 31 , pp. 67-77.

[31] Lyu, T.H. and Mudawar, I., 1991, "Statistical Investigation of the Relationship between Interfacial Waviness and Sensible Heat Transfer to a Falling Liquid Film," Int. J. Heat Mass Transfer 34, pp. 1451-1464.

[32] Lyu, T.H. and Mudawar, I., 1991, "Determination of WaveInduced Fluctuations of Wall Temperature and Convective Heat Transfer Coefficient in the Heating of a Turbulent Falling Liquid Film," Int. J. Heat Mass Transfer 34, pp. 2521-2534.

[33] Shmerler, J.A. and Mudawar, I., 1988, "Local Evaporative Heat Transfer Coefficient in Turbulent Free-Falling Liquid Films," Int. J. Heat Mass Transfer 31, pp. 731-742.

[34] Mudawar, I. and Houpt, R.A., 1993, "Mass and Momentum Transport in Falling Liquid Films Laminarized at relatively High Reynolds Numbers," Int. J. Heat Mass Transfer 36, pp. 34373448.ut references here.

[35] Derby, M., Lee, H., Peles, Y., and Jensen, M., 2012, "Condensation Heat Transfer in Square, Triangular, and SemiCircular Mini-Channels," Int. J. Heat Mass Transfer 55, pp. 187197.

[36] Fang, C., David, M., Wang, F., and Goodson, K.E., 2010, "Influence of Film Thickness and Cross-Sectional Geometry on Hydrophilic Microchannel Condensation," Int. J. Multiphase Flow 36, pp. 608-619 